\section{A Fotomontagem e o Design}

\author{
The Photomontage and Design
}

\begin{abstract}
Fotomontagem, Design, Arte
Este artigo pretende analisar a relação da fotomontagem como ferramenta de elaboração de imagens para definir conceitos e ideias. Como ferramenta, a fotomontagem liga o princípio da montagem na elaboração de imagens e ideias em meios mecânicos, como fotografia e cinema, aliando a isso novas formas de produção do design gráfico em propaganda e revistas. O principal movimento que elevou a fotomontagem à categoria de produção de ideias foi o Construtivismo Soviético, vanguarda das primeiras décadas do século XX cujo princípio norteador era a incorporação da lógica maquinicista na produção artística e fundindo o design à arte e vice-versa.
\end{abstract}

\section{Photomontage, Design , Art}

This article intends to analyze the relation of photomontage as an image elaboration tool to define concepts and ideas. As a tool, photomontage links the principle of assembly in the elaboration of images and ideas in mechanical media, such as photography and cinema, combining new forms of graphic design in advertising and magazines. The main movement that brought photomontage to the category of idea production was Soviet Constructivism, the vanguard of the first decades of the twentieth century whose guiding principle was the incorporation of maquinicist logic into artistic production and merging design with art and vice versa.

\section{Introdução:}

A fotomontagem afastou da fotografia o olhar artístico estático e pictórico que a remetia à pintura por acentuar-Ihe aquilo que mais a tornava tecnicista e industrial: a montagem de imagens e sua reprodução em série. A fotomontagem sempre fez parte do próprio mecanismo da fotografia, quando elementos externos ao fotograma eram adicionados, ao negativo ou ao positivo da exposição e captação da imagem.

O olhar estético ligado à fotografia no primeiro momento associou-a à pintura e à representação pictórica, a fotografia e a fotomontagem surgiram concomitantemente, no processo de construção do olhar fotográfico, embora seus referenciais eram estilos artísticos das belas artes, e ao registro quase naturalista da realidade. Neste artigo tenta-se argumentar, brevemente, que o olhar estético da fotografia se desenvolve para uma estética mecânica a partir do surgimento do conceito de montagem como princípio estético da era da máquina, e dos aparelhos, como se refere Vilém Flusser (1985), na sociedade industrial.

A fotomontagem está para a fotografia como a montagem está para o cinema, que desconstrói o padrão antigo da arte naturalista e pictórica das representações levando-as para elaborações conceituais. Este processo de construção de imagens através dos meios mecânicos ou aparelhos é fundamental no processo de criação e produção no design, refletido nos diversos segmentos gráficos, nas revistas, cartazes e na propaganda de agitação de conteúdo político.

Para tal juízo que pretende-se utilizar como referência as transformações artísticos e estéticas postulados nas vanguardas russas do início do século XX, principalmente o Construtivismo. $O$ construtivismo, pode-se dizer, concentrou as principais correntes e movimentos vanguardistas russos a partir da década de 20, dentre os quais podemos destacar o Suprematismo e o Produtivismo, bem como os mais do início do século como o Raionismo e o Futuro-cubismo.

\section{Fotomontagem e Foto-colagem}

O limite entre as diversas expressões artísticas que utilizam aparelhos para a representação dos seus conceitos e ideias é muito tênue, pelo fato de que técnicas e ferramentas de recorte, colagem e reprodução de imagens estão interligadas e se misturam de acordo com a intensão do produtor. Grosso modo poderíamos listar dois tipos dessas expressões artísticas: a fotomontagem, a foto-colagem. Para estas definições usaremos como referência Peter Bürger,

Anais do $8^{\circ}$ CIDI e 8 CONGIC

Guilherme Santa Rosa; Cristina Portugal (orgs.)

Sociedade Brasileira de Design da Informação - SBDI

Natal | Brasil | 2017

ISBN 978-85-212-1305-5
Proceedings of the $8^{\text {th }}$ CIDI and $8^{\text {th }}$ CONGIC

Guilherme Santa Rosa; Cristina Portugal (orgs.)

Sociedade Brasileira de Design da Informação - SBDI

Natal| Brazil | 2017

ISBN 978-85-212-1305-5 
que no seu livro Teoria das Vanguardas (2012), que postula a partir da fotomontagem, modelos diferenciados do uso da técnica de manipulação da imagem fotográfica.

Para Bürger, a fotomontagem é uma técnica, que ganha relevância artística quando é incorporada pelos movimentos modernistas de vanguardas, como o Dadaísmo, o Surrealismo e o Construtivismo. Como técnica, a fotomontagem, é classificada a partir dos estilos e de como a imagem fotográfica é construída. O conteúdo da imagem fotográfica transformada pela fotomontagem é o principal definidor do caráter de técnica aplicada ao significado da obra, a forma como os elementos fotográficos e imagéticos vão compor o objeto final é o que define a ideia final do objeto.

A fotomontagem para Bürger se define pelo seu caráter inorgânico, presente em obras artísticas da era da máquina, e que reutilizam objetos já prontos para elaborar sua obra artística. Neste sentido a fotomontagem é diferenciada pelo uso dos elementos internos da própria obra, o exemplo utilizado por Bürger é a unidade da semântica visual das obras surrealistas, John Heartfield usado como exemplo, na qual há uma mimese conferindo um caráter de referencial real ou surreal ao objeto final, mas os referentes icônicos (próximos ao que representam) estão presentes; em contrapartida as fotomontagens Dadaístas, o exemplo utilizado é Hanna Höch, nas quais há o choque entre as partes e a não integração na obra como algo único ou uma representação próxima a objetos da realidade.

Um problema encontrado na definição de Bürger(2012) é a definição de fotomontagem como técnica, neste caso se torna algo menor no processo de criação de obras e objetos artísticos, e afasta-a da visão de ferramenta transformadora do processo fotográfico. Bürger ainda vê a obra de arte produzida pela fotomontagem como objeto único e com um a semântica interna do próprio objeto. Não há, explicitamente, uma relação da fotomontagem com os aparelhos que a produzem. Em 1923, na revista NOVI LEF, Liubova Popova (1923) colocava a fotomontagem como ferramenta para a fotografia tornar-se algo para além do mero registro da luz e sua grafia química em suportes fixos.

A definição da fotomontagem utilizada aqui, se define a partir do Construtivismo, que defende a fotomontagem como ferramenta, de reelaboração e construção de um novo sentido da fotografia, e sua reprodução em meios gráficos, excluindo o seu caráter unitário e único, no mesmo sentido que a montagem fez para com o cinema, o definidor da linguagem do próprio aparelho em si mesmo.

Posto isto, há um limite entre o conceito de fotomontagem para o de foto-colagem, neste há o caráter único da obra, um significado unitário pelas colagens das várias partes, sejam estas fotografias ou objetos recortados, e o caráter expositivo da obra. Não cabe neste exemplo a manipulação das imagens e sua montagem alterando-lhes o sentido, mas o caráter único da obra, anacronicamente díspar ao que permite o meio fotográfico em sua reprodução em série e massificadora.

A foto-colagem apesar de apresentar os elementos da arte inorgânica, conceito tão caro a Bürger por ser o definidor de uma arte industrial, nega este mesmo caráter ao se reduzir a uma única obra para deleite e exposição. Este ponto é o ponto crucial para afastar a fotomontagem da foto-colagem, pois insere aquela em outro campo da estética industrial que é o design. $O$ conceito de fotomontagem dentro da era industrial e sendo elaborado pelas técnicas dos meios fotográficos prescinde de uma delimitação maquinicista da sua reprodução e exposição, afastando-a da obra de arte únitária formada por retalhos e recortes em um suporte.

O trabalho com fotografias, retalhos de imagens e objetos agregados à obra de arte é recorrente aos movimentos cubistas, futuristas e surrealistas nas primeiras décadas do século $\mathrm{XX}$, conceito como o dadaísta ready-made podia ser estendido a qualquer objeto produzido e introduzido em obras de arte, desde que alterassem o seu significado e seu sentido em relação à arte. Como no caso da foto-colagem, a colagem fotográfica também parte do princípio do uso de imagem produzindo uma obra única, o fato de usar técnicas idênticas às a da fotomontagem, entretanto objeto final é único e contemplativo.

\section{3- A fotomontagem Construtivista: Fotografia e fotomontagem}

A fotografia pode ser considerada a primeira expressão artística da era industrial, tanto pelo seu sentido de técnica de reprodução como na sua reprodução em série a partir de uma 
mesma matriz. Neste ponto fotografia e design confluem para o mesmo interesse, embora sem ainda ter a fotografia o caráter de arte manipulável e diretiva que lhe será auferido pelas vanguardas modernistas, visto que o aspecto figurativo das imagens vai se contrapondo à montagem fotográfica, composição do olhar, à fotomontagem, composição fotográfica, distinções que irão ser ressaltadas à frente.

O caráter da reprodutibilidade e sua relação com arte figurativa acadêmica ressaltado no clássico texto de Walter Benjamin, enfocando o processo industrial associado às técnicas próprias do processo fotográfico, nunca como algo dado, mas construído pelas necessidades materiais do novo medium. Diferente de Benjamin, as vanguardas construtivistas russas incorporam essa técnica como um novo olhar sobre a realidade concreta, ao definir um novo recorte sobre esta, afastando-se da veracidade narrativa da fotografia figurativa, ressaltando o seu elemento transformador ao desmascarar ou apontar a artificialidade do próprio processo de captação ilusória da fotografia.

Ao se explicitar a montagem fotográfica como uma construção de sentido a posteriori, a parti da elaboração da luz, distanciando-se do falseamento da realidade "nua e crua", e esta realidade aparecendo com efeito elucidador, como um recorte, uma opinião e direcionamento do olhar. O não mascaramento deste olhar fotográfico, o recorte da máquina mostrado como algo não aleatório, mostrado como choques de ideias compondo novas ideias e imagens.

$\mathrm{Na}$ contramão da alienação da montagem industrial, que esconde o processo e a ação do produtor, a arte industrial construía uma teoria que perfaz o caminho inverso da alienação, mostrando o trabalho humano e conceitual por trás do objeto industrial, visão esta que perpassará quase todas as produções vanguardistas russas, do cinema à Agit Prop da fotografia aos atelieres da VkhUTEMAS (Oficina superior de artes e ofícios).

O senso estético da máquina é revertido pela própria estética maquinicista e acima de tudo transformadora, o lluminismo que criara uma nova fé, afirmado por Adorno e Horkheim como alienador resumido no conceito de Indústria Cultural, na vanguarda soviética mostra-se como uma nova estética, de baixo pra cima, com o controle da máquina por aqueles que dela se utilizam contra a cegueira da indústria cultural na MassKultur (cultura de massa) as vanguardas propunham uma ProletKult (cultura do proletariado) desmascarando o uso da máquina como movimento alienante. Tal olhar crítico não passaria impune ao totalitarismo e à própria indústria cultural.

Neste ponto inserimos a dialética da imagem fotográfica e a sua essência do seu movimento se compondo de novos sentidos a partir da reelaboração de imagens ou mesmo do contraste de formas linhas e texturas, conotando uma dinâmica no olhar estático, no choque de formas e concepções conferindo-lhes novos às imagens captadas. Há uma diferenciação entre montagem fotográfica e fotomontagem, que mesmo tênue a diferenciação, faz-se necessária. A primeira não se resume apenas na técnica, mas a elaboração do ato fotográfico, um processo dialético entre o objeto que se representa, a técnica de reprodução e a visão particular daquele que fotografa. Já a fotomontagem é uma técnica de trabalhar com imagens já elaboradas compondo novos significados de acordo com a montagem, pode ser visto como ação elaborativa de objetos já fabricados, no caso imagens fotográficas e uma nova composição como informação artística.

As visões sobre esses dois processos artísticos são estendidas no construtivismo russo para além das suas possibilidades técnicas, fazendo parte de um conceito maior que é o pensamento dialético e sua relação com os objetos construídos pelo ser humano. A arte neste processo não está desvinculada das ações humanas e pode e deve ser usada como expressão de esclarecimento e transformação da sociedade, a arte é usada como elemento de propaganda e participação popular. A montagem, seja na fotografia seja no cinema é parte de um complexo maior de ferramenta crítica da sociedade e da própria história.

Rodchenko, El Lissitsky, Malevich e Stepanova elaboraram não só um projeto artístico, mas também estético sobre montagem fotográfica exemplificado na Agit Prop (programa de propaganda popular) e o Proun (programa de difusão e experimentação artística), propaganda não se dissociava do ensino (Narkompros) como ferramenta revolucionária e assertiva dos modelos da revolução que difundia. Pode-se destacar a confluência das várias expressões artísticas, inserindo-as na área do design, em específico o gráfico. Entendido como projeto indústria, o design se apropria de várias técnicas de reprodução em série, difundindo e ampliando o alcance dos objetos produzidos para este fim. A fotografia e o design são frutos do 


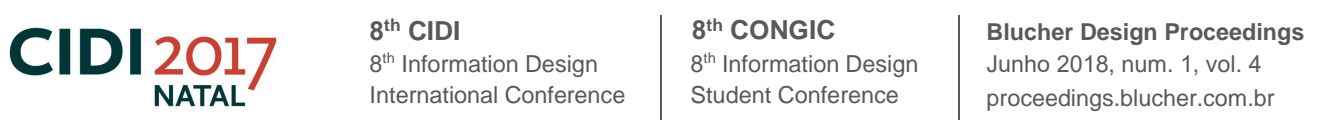

mesmo processo industrial, que populariza, distribui e para alguns diminui o valor representativo das coisas.

Os produtivistas russos tinham uma palavra para reunir todas as artes e técnicas originárias da máquina que era Poligrafia. A união do cinema, fotografia, design e propaganda política era vista como um conjunto integrado de técnicas e práticas artísticas que partiam do confronto dialético em que a composição, típica da pintura, passa a ser uma construção com choques de técnicas e ideias. Esta nova concepção de arte passa necessariamente pela máquina e esta como uma nova forma de elaborar o processo de criação, que não é mais visto como algo dado ou produto individual do artista.

A fotomontagem teria um papel primordial nesta nova visão por ser o anteposto da composição da pintura clássica, pois aquela formada de fragmentos de partes já produzidas, se afastando da ação contemplativa para uma ação produtiva e direcionada, distanciando-se de uma fotografia que aspirava ser pintura, se transformando em um novo olhar como uma síntese de várias partes integradas pelo confronto e choque do pensamento dialético.

\section{Conclusão}

O construtivismo russo que abarca as mais amplas experiências estéticas, integrando áreas como Cinema, Fotografia, artes plásticas e cênicas, ensino de artes e ofício, psicologia e pedagogia, tem por amarração o pensamento dialético que confere-lhes uma unidade conceitual e prática que pode ser resumida no conceito de montagem, não restringindo-se aos objetos artísticos mas em qualquer elaboração de artefatos nos quais o processo, a forma e a intenção não estão mascarados mas explicitados como parte integrante da maneira de pensar o mundo e dele empreender criações.

A fotomontagem surge como um novo campo de reelaboração das imagens, que confere à fotografia um novo olhar sobre o objeto construído, dando-lhe um caráter de arte, mas umas arte industrial e dinâmica longe das galerias e inseridas no dia a dia das pessoas. A arte industrial estaria presente da vida das pessoas, e não fora delas, mas acima de tudo parte de sua visão de mundo.

\section{Referências}

ADORNO, Theodor W; HORKHEIMER, Max. A dialética do esclarecimento. Rio de Janeiro: Jorge Zahar Editor, 1995.

BENJAMIM, Walter. Obras Escolhidas: Magia e Técnica, Arte e Política. Editora Brasiliense, 2010.

BENJAMIM, Walter. O arutor como produtor. In Obras escolhidas, vol. 1: Magia e técnica, arte e política. Ensaios sobre literatura e história da cultura, trad. Sérgio Paulo Rouanet, São Paulo: Editora Brasiliense, 1985; 3를. Ed., 1987, 253 pp.

BENJAMIM, Walter. Pequena História da Fotografia. In Obras escolhidas, vol. 1: Magia e técnica, arte e política. Ensaios sobre literatura e história da cultura, trad. Sérgio Paulo Rouanet, São Paulo: Editora Brasiliense, 1985; 3ª Ed., 1987, 253 pp.

BENJAMIN, W. Work of art in the age of mechanical reproduction. Media and Cultural Studies Keyworks, 48-70. http://doi.org/10.1162/grey.2010.1.39.11

BUCHLOH, B. H. D. (1990). From Faktura to Factography Author ( s ): Benjamin H . D . Buchloh Source : October, Vol . 30 ( Autumn, 1984 ), pp . 82-119 Published by : The MIT Press Stable URL : http://www.jstor.org/stable/778300

BUCHLOH, B. H. D. (1990). Institutions Conceptual Art 1962 - 1969 : From the Aesthetic of Administration to the Critique of Institutions *, 55, 105-143.

DAWN, Ades. Fotomontaje. Gustavo Gili, Barcelona, 2002.

POPOVA, Livbona. Fotomontagem. [Л. Попова. ФОТО-МОНТАЖ. Лефр. 1923 N 4. Em Леф и МАПП 


\section{CIDI 2017

[Статья], 3. http://monoskop.org/LEF\#LEF4. Baixado data: 28 nov 2015.

POUSADA, P. R. (n.d.). O INKHOUK : apontamentos sobre "a luta pela estrutura sobre o estilo " The INKHOUK: notes on " a fight for construction instead of style ," 41-67.

http://doi.org/10.5965/2175234606112014041

SÁNCHEZ-BIOSCA, V. EI montaje cinematográfico: teoría y análisis [Introducción]. Vicente SánchezBiosca, El Montaje Cinematográfico: Teoría Y Análisis [Introducción], Barcelona, Paidós, 1996, ISBN 8449303192, Pp. 15-22. Retrieved from http://roderic.uv.es//handle/10550/29911 \nhttp://roderic.uv.es/bitstream/handle/10550/29911/montaje cinematografico.pdf?sequence $=1$.

TARABUKIN, N. From the Easel to the Machine. Source: Nikolai Tarabukin, Ot mol'berta k maskine (Moscow, 1923), ch. 1-12, edited and translated by

Dr Christina Lodder. "From the Easel to the Machine", trans. Christina Lodder, in Modern Art and Modernism: An Anthology of Critical Texts, eds. Francis Frascina and Charles Harrison, London: Harper \& Row, 1983, pp 135-142, RTF. Excerpts from chs. 1-12.(English) https://monoskop.org/images/9/98/Tarabukin_Nikolai_1923_From_the_Easel_to_the_Machine.pdf.

TARABUKIN, N. The art of the day. OCTOBER 93, Summer 2000,pp. 57-77. 02000 October Magazine, Ltd. and MassachusettsInstitute of Technology.Translated by Rosamund Bartlett Introduction by Maria Gough.

TARABUKIN, N. El Ultimo Cuadro./ Por uma teoria de la pintura. Barcelona, Gustavo Gilli. 1977. "Por una teoría de la pintura", in Tarabukin, El último cuadro, ed. Andrei B. Nakov, trans. Rosa Feliu and Patricio Vélez, Barcelona: Gustavo Gili, 1977. (Catalan).

\section{Sobre o(a/s) autor(a/es)}

Paulo Diniz, Mestre, IFPE-Olinda, Brasil, paulo.diniz@olinda.ifpe.edu.br;

Paulo Cunha, PhD, UFPE, Brasil, pauloccunha@gmail.com; 